\title{
Design and analysis of a novel bolted composite $\pi$ joint under bending load
}

Longwei Zhou ${ }^{1}$, Donghua Zhang ${ }^{2}$, Libin Zhao ${ }^{1, *}$, Xiaohong Zhou ${ }^{2}$, Jianyu Zhang ${ }^{3}$, Fengrui Liu ${ }^{1}$

1 School of Astronautics, Beihang University, Beijing 100191, P.R. China

2 Beijing Electro-mechanical Engineering Institute, Beijing 100074, P.R. China

3 College of Aerospace Engineering, Chongqing University, Chongqing 400044, P.R. China

Abstract: A novel design of out-of-plane composite $\pi$ joints is proposed to elevate the load carrying capability. This design adopts an in-plane $\pi$-shaped section scheme along the loading direction to eliminate the delamination damage, which commonly occurs in traditional composite $\pi$ joints, and uses bolts to connect the joint and other structural components. Static experiments of the novel bolted composite $\pi$ joint and an aluminum counterpart were conducted. The bolted composite $\pi$ joint exhibited a larger load carrying capability with a massive weight reduction. Compared with existing static experimental results from a traditional design, the novel bolted composite $\pi$ joint also showed a greater load carrying capability. A progressive damage analysis of the bolted composite $\pi$ joint was further performed and validated by experimental data. Based on numerical simulation, the progressive damage process and failure mechanism of the bolted composite $\pi$ joint were discussed. It follows that the novel design not only eliminated potential weaknesses in deltoid fillers but also brought positive factors of composite into play and substantially strengthened the composite $\pi$ joint. Key words: Composite joint; ultimate failure; structure design; failure analysis

\section{Introduction}

With numerous applications of composite materials to the aerospace, ground transport, civil infrastructure and maritime fields $[1,2]$, the integrated composite structure technique, i.e., the fabrication of large, complex composite structures in one step, has attracted widespread attention because it can bring significant benefits, such as structural safety, low cost and light weight [3-6]. This technique remarkably evokes various creative design concepts, among which out-of-plane

*Corresponding author: Libin Zhao. E-mail: lbzhao@buaa.edu.cn 
composite joints, the effective structural connectors for integrated composite structures, have come into prominence. The out-of-plane composite joints can transmit out-of-plane load effectively and improve the structural efficiency. The joints can also reduce structural weight and simplify the assembly process. Various schemes have been proposed for the out-of-plane joints, such as T joints, L joints and $\pi$ joints, etc.

To deeply understand and further optimize the mechanical behavior of the out-of-plane joints, significant amounts of numerical analyses and experimental investigations have been carried out. Focusing on T joints and top-hat joints in ship structures, Shenoi et al. [7] and Blake et al. [8, 9] performed a series of investigations using numerical and experimental methods. Shenoi and Hawkins [7] explored the effects of material and geometric parameters on the mechanical behavior of composite $\mathrm{T}$ joints. They showed that the filler radius and the overlaminate thickness affected the structural failure significantly. Blake et al. $[8,9]$ studied the failure of $\mathrm{T}$ joints and top-hat joints using progressive damage method, which comprised of the Tsai-Hill failure criterion and a constant factor degradation model. Feih and Shercliff $[10,11]$ carried out static experiments and two-dimensional finite element analyses to explore the strength of single L composite joints under tensile and bending loads. Subsequently, an optimization design scheme of the joint was further achieved by changing the fillet shape. To make composites more affordable for aircraft, a composite adhesively-bonded $\pi$ joint possessing a low assembly cost was proposed $[12,13]$ and was further developed in the Composite Affordability Initiative (CAI) Project [14-16]. Systematic investigations to discover the potential of these composite $\pi$ joints were performed. In addition to numerous experiments, a software named as Stress-Check was developed to simulate joint failure, in which the presented interface fracture element, interface traction element and strain failure criteria were embedded [17-19]. Flansburg and Engelstad [20] investigated the failure of composite bonded $\pi$ joints in the presence of manufacturing flaws and impact damage by experiments and finite element analyses. Action and Engelstad [21, 22] presented finite element analyses combined 
with VCCT to investigate the crack arrest in composite $\pi$ joints. To deeply understand the mechanical behavior of composite $\pi$ joints, Zhao et al. [23-26], Fu et al. [27], and Zhang et al. [28] conducted systematic numerical and experimental studies on composite $\pi$ joints subjected to tensile or bending loads. They developed a three-dimensional modified maximum stress criterion and further established a commonly used progressive damage model for composite $\pi$ joints [23, 24]. Accompanied with a series of experimental investigations, they explored the mechanical behavior and failure mechanisms of $\pi$ joints under tensile or bending loads [25-27]. They also discussed the effects of geometries and materials on the failure of composite $\pi$ joints [26, 28].

A general out-of-plane composite joint comprises a vertical web, a horizontal base panel, one or two deltoid fillers and cleats (L-shaped or U-shaped), as shown in Fig. 1. In general, the base panel represents the fixed end while the vertical web is the loading position. This joint incorporates the advantage of the integrated forming technique and can be conveniently fabricated to a complex configuration, which significantly reduces the fastener numbers, weight and assembly cost. Moreover, it is able to carry and transfer high out-of-plane loads. Because of the weak interfaces and the low through-thickness performance of composites, the out-of-plane load through the interfaces between the web and the cleats, as well as through the interfaces between the base panel and the cleats, is inclined to cause delamination in the thickness direction and lead to the degradation of the mechanical behavior of the joints. This also results in rapid brittle failure, due to the low interface strength and toughness, as well as a large stress concentration [29-31].

Many methods have been proposed to overcome these aforementioned shortcomings of out-of-plane joints, especially for composite $\pi$ joints. New composite material systems were developed to provide better through-thickness properties to reduce the occurrence of delamination. Interface strength between the skin and cleats were enhanced to increase the structural load carrying capability through z-pins and stitching as well as bolted joints. Some advanced manufacturing techniques, such as three-dimensional braiding techniques, were developed to make the $\pi$-shaped 
overlaminate as an entire part and decrease the occurrence of cracks. Additionally, novel structural designs were proposed, such as bio-inspired design. To explore the efficacy of these methods, many numerical and experimental investigations were performed. Koh et al. [32-34] implemented pull-off static experiments and finite element analyses of $\mathrm{T}$ joints, which were reinforced using z-pins along the skin-stiffener bond-line. They found that z-pins hardly improved the initial stiffness and initial failure load of the $\mathrm{T}$ joints but greatly increased the ultimate failure strength, failure displacement, and energy absorption capability of the joints. Shroff and Kassapoglou [35] presented an optimized composite $\pi$ joint to connect the grid-stiffened fuselage with the passenger floor. They adopted bolts to link the joint with other structural components for easy disassembly, repair and replacement. Soden et al. [36] and Yang et al. [37] compared the failure of 3D-woven/braided composite T joints with 2D laminate composite $\mathrm{T}$ joints. They all found that the strength of $3 \mathrm{D}$ woven/braided composite $\mathrm{T}$ joints is superior to their laminate counterparts. In addition, the premature cracks in traditional 2D laminate $\mathrm{T}$ joints were avoided in 3D woven/braided $\mathrm{T}$ joints. Taylor and Owens [38] focused on efforts to develop and calibrate a set of parameterized finite element analysis handbooks for structural analyses of three dimensional $\pi$-shaped carbon fiber textile preform joints. Based on a bio-inspired design, Burns et al. [29, 30] designed a new composite $\mathrm{T}$ joint to reinforce the load carrying capability, which mimicked tree branch-trunk links by embedding the stiffener flange into the skin plies of the joint. This design was able to prevent delamination along the interface with crack branching and deflection and considerably reinforce the fracture toughness of the joint. Fan et al. [39] investigated a bolted composite $\pi$-shaped joint under bending load by experiments and progressive damage analyses. They concluded that the delamination in the fillet region of L-prepreg led to the final failure. And the delamination damage growth rapidly from initiation to final failure while the bolt hole kept intact.

In many aerospace structures, $\pi$ joints play an important role in transferring bending load between two orthogonally placed members. For example, the $\pi$ joints can be used to connect the 
wing with the fuselage and transmit bending load. Therefore, the bending load carry ability and failure modes limit the application of composite $\pi$ joints in aerospace structures. In order to fully explore the potential of the composite $\pi$ joints and improve the capability of carrying and transferring large bending load, a novel hybrid bolted composite $\pi$ joint was proposed. One specimen was fabricated, and a static experiment was carried out to verify the design while an aluminum counterpart was made and tested for comparison. To obtain a deep insight into joint failure, a progressive damage model was established, which comprised of a 3D FE model, a 3D Hashin-type failure criterion and a micromechanics based material degradation model. A progressive damage analysis was further executed to understand the failure process and failure mechanism of the novel bolted composite $\pi$ joint.

\section{Design of joint configuration}

For a traditional out-of-plane composite $\pi$ joint, load applied to the joints are transferred through different components, among which the co-curing interfaces are the weak spots. During the loading process, the $\pi$ joints are essentially subjected to a direct peeling load, which leads to significant peeling stresses at the tips [40]. Previous physical experiment results in Refs [8-11, 24-26] have also shown that the out-of-plane load mainly leads to delamination in overlaminates, filler-to-overlaminate cracking and filler cracking in the joints. In view of these load carrying and transferring characteristics in the out-of-plane joints, a novel composite $\pi$ joint subjected to bending loads has been designed to inhibit delamination and increase the load carrying capability, which takes advantage of the in-plane mechanical behavior of composites and eliminates the weakness of traditional out-of-plane composite $\pi$ joints. In this design, unidirectional composite prepregs were first tailored into $\pi$-shaped leafs with various fiber directions, which mainly include $0^{\circ}, \pm 45^{\circ}$ and $90^{\circ}$ plies. Then, the $\pi$-shaped leafs were stacked into $\pi$-shaped laminates according to a preset stacking sequence and thickness, which were called sub-components, as shown in Fig. 2(a). Moreover, a group of $\pi$-shaped composite laminates were compacted along the thickness direction 
of the laminates as per the actual application requirements, which formed the central framework of the joint as shown in Fig. 2(b). The processing approach from the sub-components to an integral structure minimizes the influence of manufacturing defects on the structural performance. The central framework was further wrapped with several layers of composite plain clothes (named the surface skin) to restrain delamination. Thus, the novel adhesively bonded $\pi$-shaped joint shown in Fig. 2(c) was achieved.

Obviously, the $\pi$-shaped section and stacking direction ensure that the $\pi$ joint transfers load among the in-plane $\pi$ section rather than the through-thickness direction of the composite laminates, which remarkably decreases the peeling stress in the joints. In addition, the potentially weak deltoid fillers in the traditional $\pi$ joints were eliminated in the novel design scheme, which considerably reduced the delamination damage and increased the strength of out-of-plane composite joints. Moreover, the surface skin provided protection for the central framework and brought down the interlamination damage in the central framework.

Furthermore, because the mechanical composite joints provide large load transfer ability and are easily detected and maintained, a bolted $\pi$ joint was adopted in the novel design. Several bolt holes shown in Fig. 2(d) were drilled for connecting the $\pi$ joint with other structural components.

\section{Specimens and static experiments}

\subsection{Specimens}

A specimen was fabricated according to the aforementioned design, and the geometric dimensions are shown in Fig. 3. The joint consisted of a central framework and a surface skin. The former was comprised of five duplicate $\pi$-shaped sub-components; each was made of a unidirectional T700 carbon/epoxy composites with a stacking sequence of $[45 / 0 /-45 / 90]_{20}$ s. The surface skin was made of G0814 carbon/epoxy composite plain clothes with a stacking sequence of $\left[(0 / 90)_{\mathrm{f}}\right]_{4}$ and a total thickness of $1 \mathrm{~mm}$. The material properties of the unidirectional composite and the composite plain cloth are listed in Table 1. The elastic moduli of the carbon fiber and epoxy resin are 235GPa and 
3.2GPa, respectively, and the fiber volume fraction is $60 \%$. Several holes were drilled in the component, with diameters of $8.3 \mathrm{~mm}$ in the lugs and $6.2 \mathrm{~mm}$ in the base panel.

Moreover, an all-aluminum counterpart, which has the same geometry and dimensions as the bolted composite $\pi$ joint shown in Fig. 3, was manufactured and tested to provide a comparison of mechanical performance.

\subsection{Loading scheme and setups}

To test the bending performance of the novel bolted composite $\pi$ joint, a set of metal jigs were designed and manufactured for supporting and loading according to the practical application of the joint. Fig. 4 illustrates the loading scheme and setups. The jigs were comprised of a steel cantilever beam, a steel L-shaped support plate and a steel base plate. The steel base plate was fixed on the benchmark of the test machine, and the L-shaped support plate was fastened with the base plate. The $\pi$ joint was further fixed on the L-shaped support plate by twelve titanium bolts with diameter of $6.2 \mathrm{~mm}$. A cantilever beam was introduced into the two lugs of the joint by two 30CrMnSiA steel bolts with diameter of $8.3 \mathrm{~mm}$. A compression load was applied to the top side of the cantilever beam by the loading head of the machine, which formed the bending load applied to the $\pi$ joint.

\subsection{Experiment procedures}

Static tests of the composite and aluminum specimens were implemented in a $100 \mathrm{kN}$ servo universal testing machine (DDL100) with displacement control mode at a constant crosshead speed of $1 \mathrm{~mm} / \mathrm{min}$. A quasi-static compressive load was applied to the upper surface of the steel single cantilever beam with a distance of $248 \mathrm{~mm}$ from the bottom surface of the $\pi$-shaped component. The applied load and displacement of the crosshead were automatically recorded by a digital data acquisition system. The damage and failure processes of the joint during the tests were recorded by videos and photographs. The peak value of the load-displacement curve was defined as the final failure load of the joint.

\subsection{Experimental results}


Fig. 5 shows the load-displacement curves of both the composite and aluminum $\pi$ joint specimens. The curve was nearly linear before the first load drop for the composite joint, during which no visible damage appeared on the surface of the joint. After that, a series of slight load drops happened before the ultimate failure of the joint. As each load drop occurred, some noises were emitted and obvious cracks appeared on the surface, which were accompanied by a gradual stiffness degradation of the joint. As the load increase, bumps on the top surface of the left lug appeared and the some bolts at the base panel deformed seriously. With respect to the aluminum $\pi$ joint, the load-displacement curve exhibited a small initial linear stage, followed by an obvious non-linear degradation of stiffness; then the joint entered into an evident yielding status. The ultimate failure load of the composite $\pi$ joint was $13.31 \mathrm{kN}$, which was $21.3 \%$ higher than that of the aluminum $\pi$ joint $(10.97 \mathrm{kN})$. In addition, the weight of the composite specimen was approximately $45 \%$ lighter than that of the aluminum specimen. It follows that the composite $\pi$ joint offered a higher stiffness and ultimate failure load, while having a lighter weight than the aluminum $\pi$ joint. Moreover, a traditional design of the composite $\pi$ joint developed in Ref. [39], which has the same geometry but with a very low ultimate failure load of $7.5 \mathrm{kN}$, is compared with the novel joint in the current work. Obviously, a $77.5 \%$ increment of the ultimate failure load was obtained using the novel design.

Fig. 6 gives the side profile comparison of the composite and aluminum $\pi$ joint specimens after tests. It can be found that the aluminum specimen exhibited a large plastic deformation at the base panel and the lugs, as well as the regions around the bolt holes. However, no obvious deformation can be observed in the composite specimen, its failure configuration is similar with the original one after unload. Moreover, scathe around the holes in the aluminum specimen was hardly observed, while significant shear and bearing damage occurred around the holes in the lugs and the base panel of the composite specimen. Otherwise, bumps on the top surface of the left lug and obvious deformation of holes both in the lugs and the base panel can be found. The damage around holes at the top side of the joint as shown in Fig. 4 is much more serious than that of the upside one. There is 
substantial surface cracking can be found at the right outer fillet.

\section{Progressive damage analysis of the novel bolted composite $\pi$ joint}

Although the failure load, load-displacement curve and failure pattern can be obtained from experiments, knowledge of the detailed failure process cannot be acquired. The progressive damage method, which can trace the failure history from the damage onset to the ultimate collapse, is useful to further investigate the failure mechanism of the joint. A progressive damage model was established for the novel bolted composite $\pi$ joint, which included a three-dimension finite element model, a Hashin-type failure criterion and a micromechanics-based degradation model.

\subsection{Finite element model}

A three-dimensional finite element model of the specimen was established using the ABAQUS ${ }^{\circledR}$ software package, as shown in Fig. 7. Because of the geometric complexity and the diversity of the stacking direction in the novel joint, the material orientations and the corresponding local coordinates were carefully set according to the design scheme. As shown on the left side of Fig. 7, the rectangular and cylindrical coordinates were arranged in different parts of the joint to match the material principal axes of the surface skin and the central framework. In addition, fine meshes were designed around the bolt holes and the fillets between the lugs and the base panel to capture the stress concentration of contact surfaces, which were the critical areas with high stress concentrations. The meshes carefully matched the complex geometric shape and the orthogonal stacking direction in the central framework and the surface skin.

The metal jigs and bolts in the model were considered to be linear elastic and there is no damage involved. To simplify the finite element model, the horizontal parts of the L-shaped support plate and the base plate shown in Fig. 4 were neglected in the numerical model. The bottom end surface of the left metal plate of the L-shaped support was fixed to simulate the constraints of the joint. To model the loading and the actual load transferring path, a single cantilever beam was modeled exactly, and a displacement load was applied to the upper side. Contact pairs with surface to surface 
contact technique were defined between each part of the structure, as shown by the red lines in the upper right corner of Fig. 8. The tangential behavior was defined as a friction factor of 0.3 by penalty formulation while the normal behavior was defined as hard contact. Each pair of the bolt and nut was modeled as one unit to reduce the contact pairs and the computational cost.

In order to avoid the element distortion caused by the high aspect ratio of elements and the huge computation cost when using a layer of mesh represents a single composite ply, one element with several plies through the thickness and the Composite Layup function in ABAQUS ${ }^{\circledR}$ were employed. Eight-node solid elements C3D8 with three displacement degrees of freedom per node were adopted to model the specimen and jigs. Based on the mesh sensitivity analysis, the mesh with 85364 elements and 99815 nodes was adopted for the bolted composite $\pi$ joint to obtain a convergence result.

\subsection{Failure criterion and material degradation model}

Among the various failure criteria and degradation models for different composite structures, the three-dimensional Hashin-type failure criterion is deemed to be one of the best criteria to examine failure and distinguish failure modes [41]. The Hashin-type failure criterion modified by Tserpes [42] was adopted in the current investigation because it contains most of the existing failure modes. The failure criterion is depicted as follows.

Fiber tension $\left(\sigma_{11}>0\right)$ :

$$
\left(\sigma_{11} / X_{\mathrm{T}}\right)^{2}+\left(\tau_{12} / S_{12}\right)^{2}+\left(\tau_{13} / S_{13}\right)^{2} \geq 1
$$

Fiber compression $\left(\sigma_{11}<0\right)$ :

$$
\left(\sigma_{11} / X_{\mathrm{C}}\right)^{2} \geq 1
$$

Matrix tension $\left(\sigma_{22}>0\right)$ :

$$
\left(\sigma_{22} / Y_{\mathrm{T}}\right)^{2}+\left(\tau_{12} / S_{12}\right)^{2}+\left(\tau_{23} / S_{23}\right)^{2} \geq 1
$$

Matrix compression $\left(\sigma_{22}<0\right)$ :

$$
\left(\sigma_{22} / Y_{\mathrm{C}}\right)^{2}+\left(\tau_{12} / S_{12}\right)^{2}+\left(\tau_{23} / S_{23}\right)^{2} \geq 1
$$

Fiber-matrix shear-out $\left(\sigma_{11}<0\right)$ :

$$
\left(\sigma_{11} / X_{\mathrm{C}}\right)^{2}+\left(\tau_{12} / S_{12}\right)^{2}+\left(\tau_{13} / S_{13}\right)^{2} \geq 1
$$

Interlaminar tension $\left(\sigma_{33}>0\right)$ :

$$
\left(\sigma_{33} / Z_{\mathrm{T}}\right)^{2}+\left(\tau_{13} / S_{13}\right)^{2}+\left(\tau_{23} / S_{23}\right)^{2} \geq 1
$$


Interlaminar compression $\left(\sigma_{33}<0\right): \quad\left(\sigma_{33} / Z_{\mathrm{C}}\right)^{2}+\left(\tau_{13} / S_{13}\right)^{2}+\left(\tau_{23} / S_{23}\right)^{2} \geq 1$

When the failure criterion is satisfied during the progressive damage analysis, the material is diagnosed to fail, and the properties of the damaged material are modified according to a set of material degradation rules. A micromechanics-based material degradation model proposed by Zhang et al. [43] was adopted in the current investigation. In the model, the material degradation factors can be conveniently determined by only fundamental material properties, including the unidirectional lamina material properties and the elastic moduli of the fiber and the matrix, as well as the fiber volume fraction. For the composite plain cloth, a stiffness degradation model used in Ref. [44, 45] was adopted in the current work. According to the references, the fiber matrix shear-out failure mode was not considered. In addition, the load capability of the element was assumed to be totally lost when a combination of different tension failure modes occurred.

In Eqns. (1)-(7) and Table 2, the index 1 stands for the fiber direction, 2 for the transverse direction and the index 3 denotes the through-thickness direction in the local material coordinate systems. $X_{\mathrm{T}}$ and $X_{\mathrm{C}}$ are the tensile and compressive strengths in the fiber direction, respectively; $Y_{\mathrm{T}}$ and $Y_{\mathrm{C}}$ are the tensile and compressive strengths in the transverse direction, respectively; $Z_{\mathrm{T}}$ and $Z_{\mathrm{C}}$ are the tensile and compressive strengths in the through-thickness direction, respectively; and $S_{12}$, $S_{13}, S_{23}$ are the shear strengths. The superscript ' $d$ ' denotes the material properties after degradation.

\subsection{Result and discussion}

Fig. 8 shows the load-displacement curves obtained from the progressive damage analysis and the experiment for the novel bolted composite $\pi$ joint under a bending load. The predicted curve shows that the joint experienced a long linear stage before approaching the maximum load, around which the stiffness degraded quickly, and an obvious nonlinear behavior was observed. According to the numerical simulation, the ultimate failure occurred when the applied load reached $12.50 \mathrm{kN}$, after which a rapid load drop appeared and the calculation stopped, meaning that the joint had lost its load carrying ability. Although the small intermittent load drops in the experiment were not 
captured, the numerical curve is in good agreement with the experimental result. In addition, the relative error of the ultimate failure load between the numerical and experimental results is about $-6.1 \%$, which further provides evidence of the effectiveness of the progressive damage model.

In order to understand the failure of the composite $\pi$ joint under bending load, the failure location, failure pattern and damage propagation process until ultimate failure were traced during the progressive damage analysis. Fig. 9 schematically illustrates the typical damage evolution patterns.

When the applied load reached $4.30 \mathrm{kN}$, initial damage was detected around the bolt holes on the left lug of the central framework, as shown in Fig. 9(a). As the bending load increased, the damage around the bolt holes rapidly extended upwards and then propagated into the surface skin. When the load increased to $6.18 \mathrm{kN}$, new damage as shown in Fig. 9(b) appeared around the holes in the surface skin of the base panel. By further increasing the bending load, three damage spots appeared at the outside corner between the right lug and the base panel, related to the positions of the bolt holes in the base panel, shown in Fig. 9(c). Soon afterwards, the damage spots became connected along the transverse direction of the fillet and propagated into the central framework. When the load reached $9.72 \mathrm{kN}$, damage appeared at the left side of the bottom surface of the base panel, and then damage appeared at the corresponding left outside fillet shown in Fig. 9(d). Afterwards, the damage around the fastener holes in the left lug extended to the top surface of the lug and resulted in two strip-shaped damage zones shown in Fig. 9(e). Then, the damage at the left outside fillet propagated into the central framework and broke through the thickness of the base panel while damage occurred at the right side of the bottom surface shown in Fig. 9(f), which further led to the final load drop in the load-displacement curve. It follows that the main failures occurred at the holes on the left base panel, the fastener holes in the left lugs, and the outside fillet between the right lug and the base panel.

Based on the experimental and progressive damage analysis results, the proposed novel bolted composite $\pi$ joint was validated to be effective in transferring an out-of-plane bending load. The 
load carrying capability was increased approximately $78 \%$ compared with that from the traditional design scheme and approximately $21 \%$ compared to the metal counterpart, while exhibiting a $45 \%$ weight reduction. Fig. 10 gives the comparison of ultimate failure pattern of experiment and progressive damage analysis and a good agreement was obtained. Obvious bumps on the top surface of the left lug and shear-out can be found. Some surface cracks occurred at the right outer fillet (which is the lower side during test and sustained compression load). However, the surface of the left outer fillet is smooth but the color of some regions changed into yellow, it may be caused by the fiber breakage. Serious delamination damage can be found around the holes at the left side of the base panel (which is the upper side during test), especially the holes near the fillet. Furthermore, some surface cracks appeared between two rows of bolt holes. There is no obvious damage can be found at the right side of the base panel.

A detailed load transfer path is analyzed here for further creative optimization of the novel composite $\pi$ joint. The out-of-plane load was applied to the top side of the metal cantilever beam, which was transferred to the composite $\pi$ joint by two bolts in the lugs. Then, the load was further transferred to the base panel by the out-of-plane joint and then to the fixation by several bolts on the base panel. In this load transferring path, the bolt holes and the outer right fillet were critical links because these zones had high stress concentrations, and bearing or delamination damage easily appeared. Because the novel composite joint adopted an in-plane $\pi$-shaped section design scheme, the delamination damage in the traditional deltoid filler regions was eliminated successfully, which was instrumental in elevating the load carrying capability of the joint. In fact, the joint exhibited obvious bearing damage around the bolt holes. This failure mode was an expected one for designers because the bearing failure is a gradual failure mode, which can provide a failure alert for the safety of integrated composite structures. At the same time, increasing the thicknesses of the surface skin and the base panel can further improve the load carrying capability of the joint. Moreover, adjusting the locations of the holes and the fillet radius can relieve the high stress concentrations to some 
extent and also be beneficial for enhancing the joints.

\section{Conclusions}

To significantly improve the load carrying capability of composite $\pi$ joints, a novel design is presented in this paper, which takes advantages of the in-plane properties of composites and successfully eliminates the failure of deltoid fillers occurring commonly in traditional $\pi$ joints. According to this design, a new bolted composite $\pi$ joint was designed, fabricated and tested. The experimental results show that the new joint exhibits a higher load carrying capability with little deformation, as well as a remarkable weight reduction compared with its aluminum counterpart. Moreover, in contrast to the traditional composite $\pi$ joint, the new joint provides a considerably larger ultimate failure load while maintaining a similar structural weight. Furthermore, in order to deeply probe into the failure process and failure mechanism of the novel bolted composite $\pi$ joint, a progressive damage model of the joint was established, and the progressive damage analysis results were validated by the static experimental results. From the numerical simulation, it follows that in the novel bolted composite $\pi$ joint, catastrophic failure, such as delamination and cracking propagation, was inhibited and changed to non-catastrophic bearing failure around the bolt holes, which is beneficial for the safety of integrated composite structures.

\section{Acknowledgements}

This work is supported by the National Science Foundation of China (11372020 and 11572058).

\section{Reference}

[1] Banea MD, da Silva LFM. Adhesively bonded joints in composite material: An overview. P I Mech Eng L-J Mat 2009; 223(1):1-18.

[2] Thoppul SD, Finegan J, Gibson RF. Mechanics of mechanically fastened joints in polymer-matrix composite structures-A review. Compos Sci Technol 2009; 69: 301-29.

[3] Holzwarth RC. The structural cost and weight reduction potential of more unitized aircraft structure. AIAA-1998-1872. 
[4] Tay TE, Liu G. Progressive failure analysis of composite. Journal of Composite Materials 2008; 42(18):1921-66.

[5] Musicman A, Reinsert H. Composite wing/fuselage integral concept. AIAA-1980-0744.

[6] Pei JH, Shenoi RA. Examination of key aspects defining the performance characteristics of out-of-plane joints in FRP marine structures. Compos Part A 1996; 27(A):89-103.

[7] Shenoi RA, Hawkins GL. Influence of material and geometry variations on the behavior of bonded tee connections in FRP ships. Compos 1992; 23(5):335-45.

[8] Black JIR, Shenoi RA, House J, Turton T Progressive damage analysis of tee-joints with viscoelastic inserts. Compos Part A 2001; 32: 641-53.

[9] Black JIR, Shenoi RA, House J, Turton T. Strength modeling in stiffened FRP structures with viscoelastic inserts for ocean structures. Ocean eng 2002; 29: 849-69.

[10] Feih S, Shercliff HR. Composite failure prediction of single-L joint structures under bending. Compos Part A 2005; 36: 381-95.

[11] Feih S, Shercliff HR. Adhesive and composite failure prediction of single-L joint structures under tensile loading. Int J Adhes Adhes 2005; 25: 47-59.

[12] Sheahen P, Bersuch L. Robust composite sandwich structures. AIAA-1998-1873.

[13] Sheahen P, Schmidt R. Primary sandwich structure: a unitized approach. AIAA-2000-1430.

[14] William B, Ken L. Composite affordability initiative phase I: concept design maturation. AIAA-1998-1874.

[15] Butler B. Composite affordability initiative. AIAA-2000-1379.

[16] Forster E, Clay S, Holzwarth R, Pratt D, Paul D. Flight vehicle composite structures. AIAA-2008-8976.

[17] Engelstad SP, Berry OT. A high fidelity composite bonded joint analysis validation study-part I: analysis. AIAA-2005-2166.

[18] Deobald LR, Mabson GE, Dopker B, Fogarty M, Renieri GD, Kennett M. High fidelity 
composite bonded joint analysis validation study part II: analysis correlation. AIAA-2007-2190.

[19] Engelstad SP, Mollenhauer DH, Berry OT, Colleary AJ. Comparisons of measured moire fringe surface strains and model predictions for a co-bonded pi-preform composite tee joint. AIAA-2004-1561.

[20] Flansburg BD, Engelstad SP. Robust design of composite bonded pi joint. AIAA-2009-2447.

[21] Action JE, Engelstad SP. Crack arrestment of bonded composite joints. AIAA-2013-1876.

[22] Action JE, Engelstad SP. Crack arrestment of pi-joined bonded composites. AIAA-2014-1380.

[23] Zhao LB, Qin TL, Zhang JY, Shenoi RA. Modified maximum stress failure criterion for composite $\pi$ joints. J Compos Mater 2013; 47(23): 2995-3008.

[24] Zhao LB, Qin TL, Chen YL, Zhang JY. Three dimensional progressive damage models for cohesively bonded composite $\pi$ joint. J Compos Mater 2014; 48(6): 702-21

[25] Zhao LB, Qin TL, Shenoi RA, Zhang JY, Liang XZ, Huang H. Strength Prediction of Composite П Joint under Tensile Load. J Compos Mater 2010; 44(23): 2759-78.

[26] Zhao LB, Gong Y, Qin TL, Mehmood S, Zhang JY. Failure prediction of out-of-plane woven composite joints using cohesive element. Compos Struct 2013; 106: 407-16.

[27] Fu Y, Zhang JY, Zhao LB. Strength prediction of composite $\pi$ joint under bending load and study of geometric and material variations effects. J Compos Mater 2013; 47(8): 1029-38.

[28] Zhang JY, Zhao LB, Qin TL, Fu Y, Fei BJ. Influence of $\pi$ overlaminates on the mechanical behavior of all-composite adhesively bonded $\pi$ joints. J Reinf Plast Comp 2014; 33(10): 923-34.

[29] Burns LA, Mouritz AP, Pook D, Feih S. Bio-inspired design of aerospace composite joints for improved damage tolerance. Compos Struct 2012; 94: 995-1004.

[30] Burns LA, Mouritz AP, Pook D, Feih S. Bio-inspired hierarchical design of composite T-joints with improved structural properties. Compos Part B 2015; 69: 222-31.

[31] Tserpes KI, Ruzek R, Mezihorak R, Labeas GN, Pantelakis Sp. The structural integrity of a novel composite adhesively bonded flap-track beam. Compos Struct 2011; 93: 2049-59. 
[32] Koh TM, Feih S, Mouritz AP. Experimental determination of the structural properties and strengthening mechanisms of z-pinned composite T-joints. Compos Struct 2011; 93: 2222-30.

[33] Koh TM, Isa MD, Feih S, Mouritz AP. Experimental assessment of the damage tolerance of z-pinned T-stiffened composite panels. Compos Part B 2013; 44: 620-7.

[34] Bianchi F, Koh TM, Zhang X, Partridge IK, Mouritz AP. Finite element modelling of z-pinned composite T-joints. Compos Sci Technol 2012; 73: 48-56.

[35] Shroff S, Kassapoglou C. Designing highly loaded connections in a composite fuselage. J Aircraft 2014; 51(3): 833-40.

[36] Soden JA, Weissenbach G, Hill BJ. The design and fabrication of 3D multi-layer woven T-section reinforcements. Compos Part A 1999; 30: 213-20.

[37] Yang QD, Rugg KL, Cox BN, Shaw MC. Failure in the junction region of T-stiffeners: 3D-braided vs. 2D tape laminate stiffeners. Int J Solids Struct 2003; 40: 1653-68.

[38] Taylor RM, Owens SD. Correlation of an analysis tool for 3-D reinforced bonded joints on the F-35 joint strike fighter. AIAA-2004-1562.

[39] Fan JF, Cheng XQ, Wang SW, Guo X, Zhang T. Experimental and numerical investigation of composite bolted $\pi$-joint subjected to bending load. Compos Part B 2015; 78: 324-30.

[40] Ji W, Waas AM. Progressive failure analysis method of a pi joint with uncertainties in fracture properties. AIAA-2012-1544.

[41] Tserpes KI, Papanikos P, Kermanidis T. A three-dimensional progressive damage model for bolted joints in composite laminates subjected to tensile loading. Fatigue Fract Eng Mater Struct 2001, 24(10): 663-75.

[42] Tserpes KI, Ruzek R, Pantelakis Sp. Strength of pi shaped non-crimp fabric adhesively bonded joints. Plast Rubber Compos 2012; 41(2): 100-106.

[43] Zhang JY, Zhou LW, Chen YL, Zhao LB, Fei BJ. A micromechanics-based degradation model for composite progressive damage analysis. J Compos Mater Doi: 10.1177/0021998315602947. 
[44] Reddy YS, Reddy JN. Three-dimensional finite element progressive failure analysis of composite laminates under axial extension. Compos Tech and Res 1993; 15(2): 73-87.

[45] Yang B, Wang ZQ, Zhou .M, Feng JF, Liang WY. Experimental and numerical investigation of interply hybrid composites based on woven fabrics and PCBT resin subjected to low-velocity impact. Compos Struct 2015; 132: 464-76. 


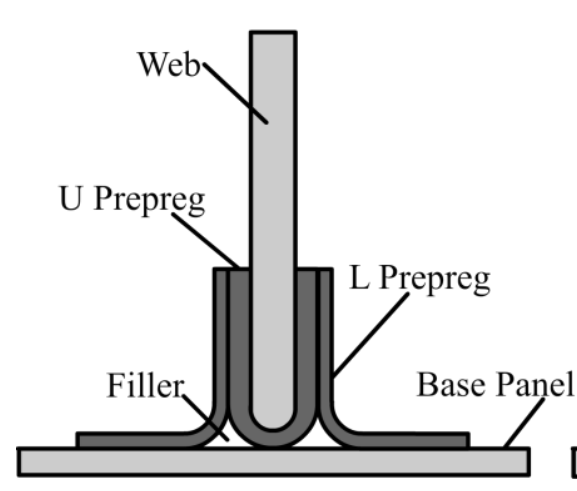

$\pi$-shaped joint

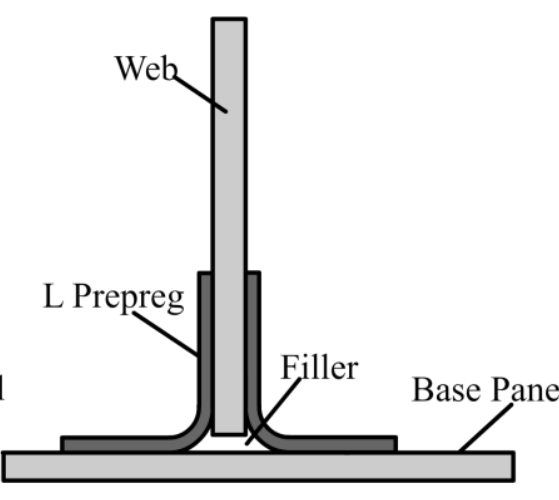

T-shaped joint

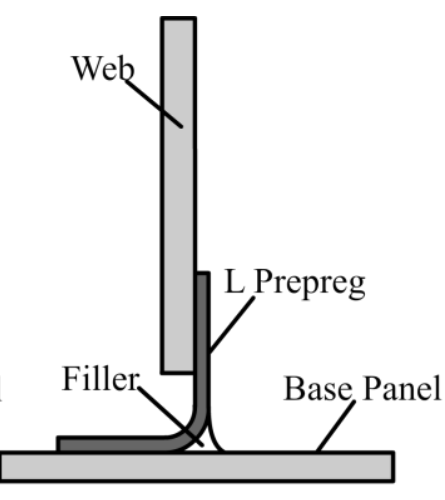

L-shaped joint

Figure 1. Typical configurations of out-of-plane composite joints

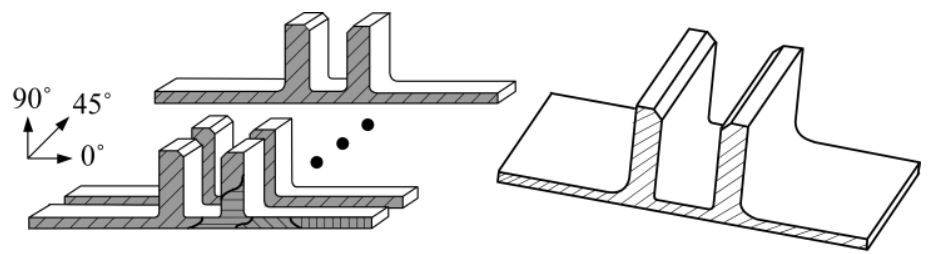

(a)

(b)

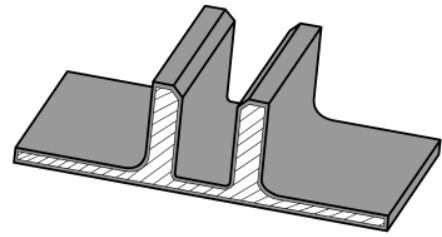

(c)

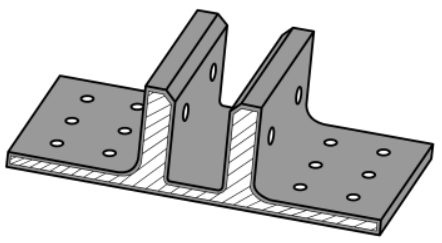

(d)

Figure 2. Schematic diagrams of design and fabrication for a novel bolted composite $\pi$ joint: (a) composite $\pi$-shaped sub-components; (b) $\pi$-shaped central framework; (c) adhesively bonded $\pi$ joint wrapped with composite plain cloth (d) a bolted composite $\pi$ joint 


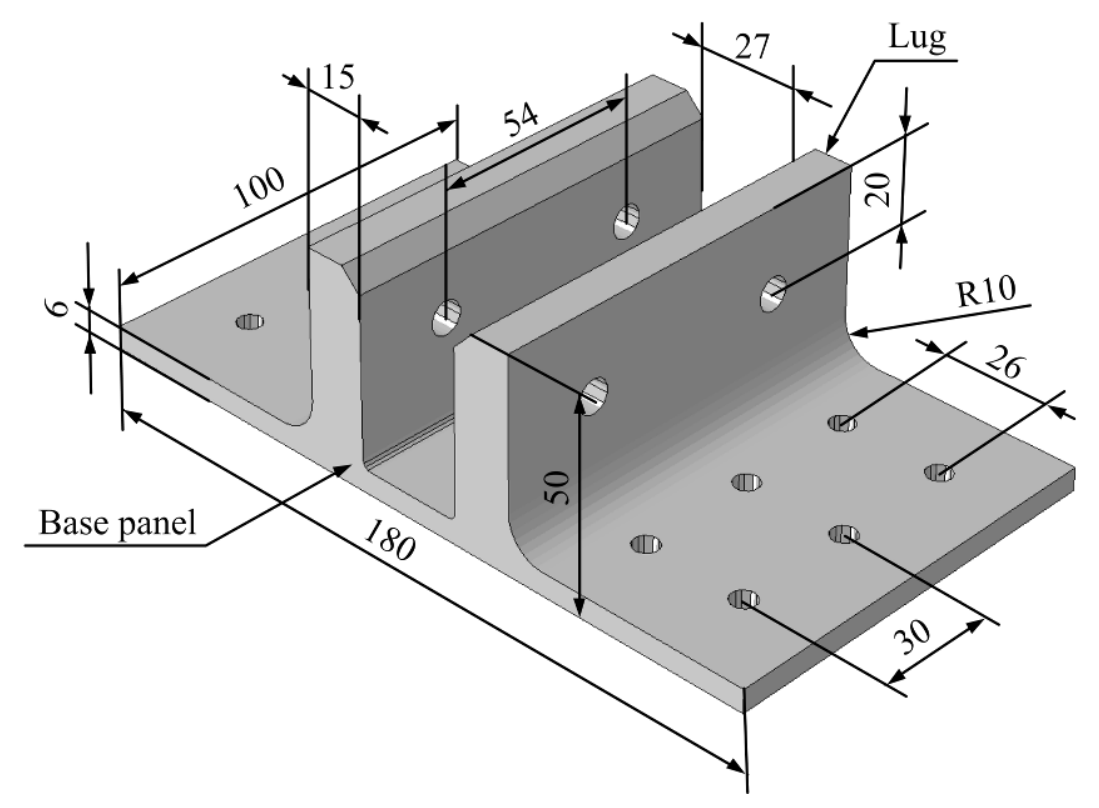

Figure 3. Geometric dimensions of composite bolted $\pi$ joint (unit: $\mathrm{mm}$ )

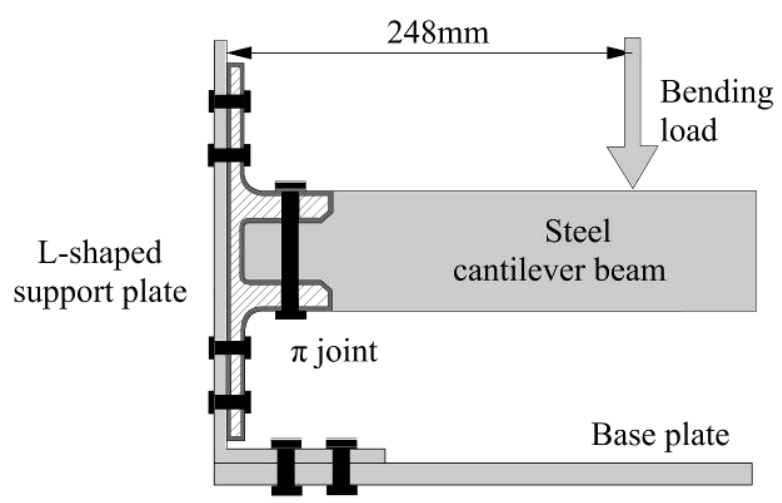

(a)

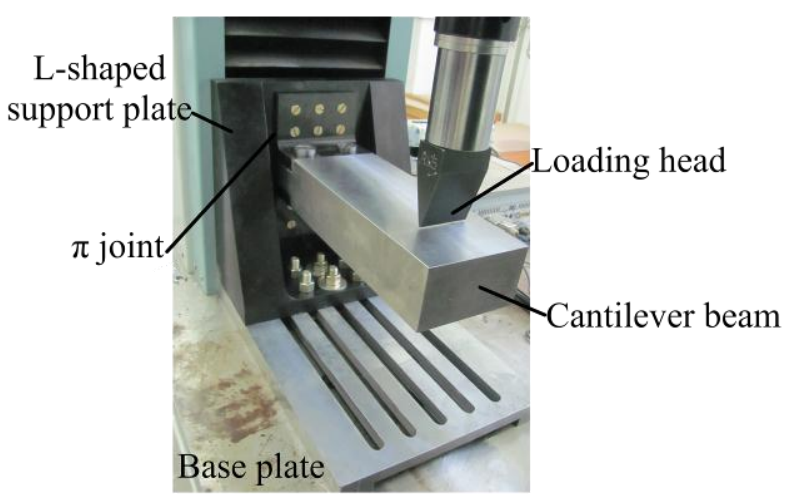

(b)

Figure 4. Experimental schematic diagram: (a) loading scheme; (b) experimental setups 


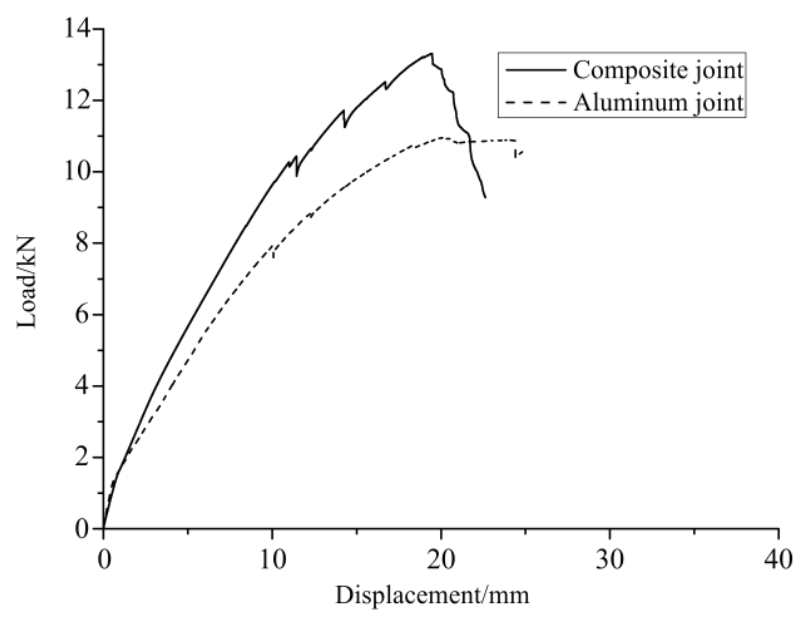

Figure 5. Experimental load-displacement curves

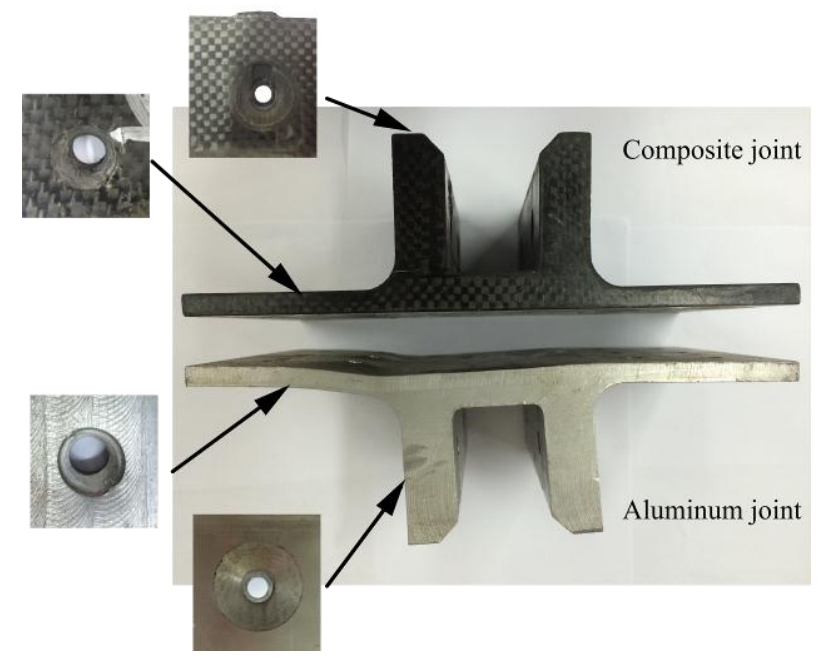

Figure 6. Comparison of specimens after unloading 


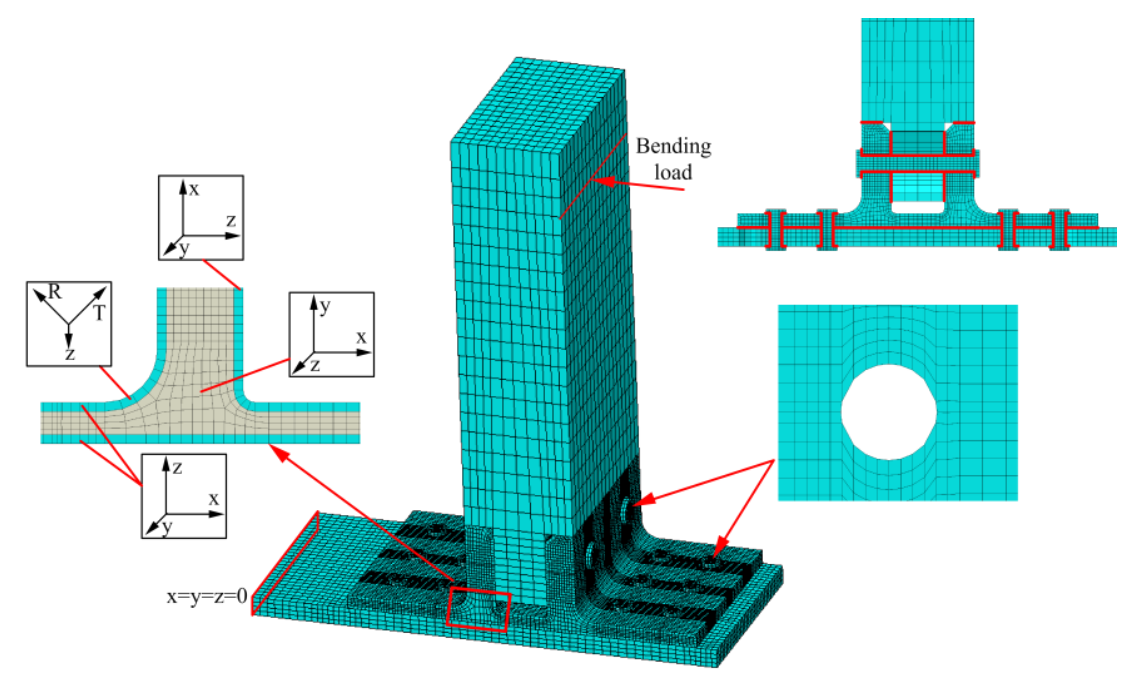

Figure 7. Finite element model of bolted composite $\pi$ joint under bending loading

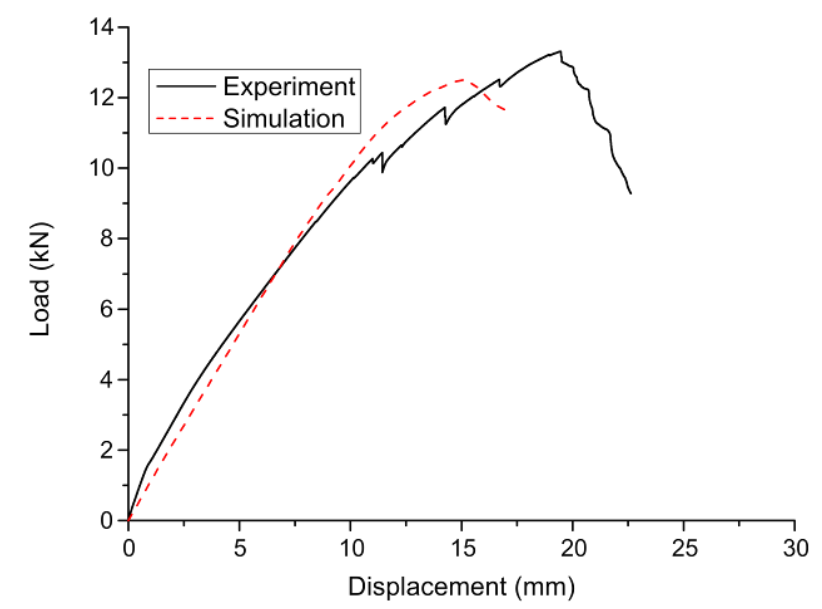

Figure 8. Comparison of experimental and predicted load-displacement curves 


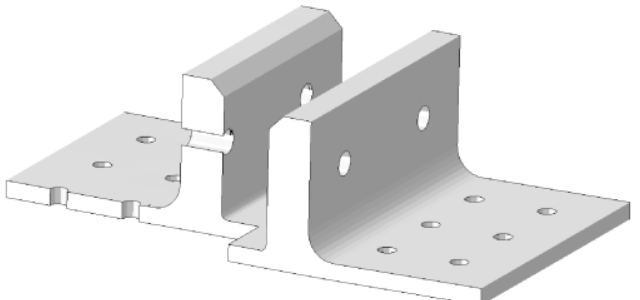

(a)

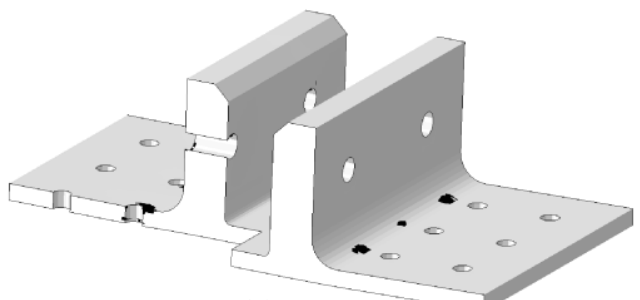

(c)

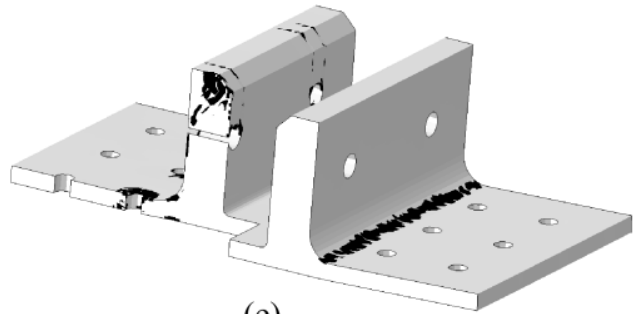

(e)

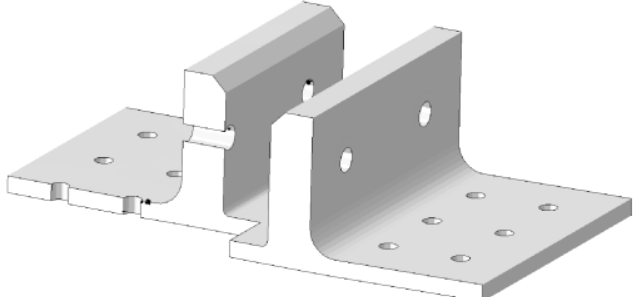

(b)

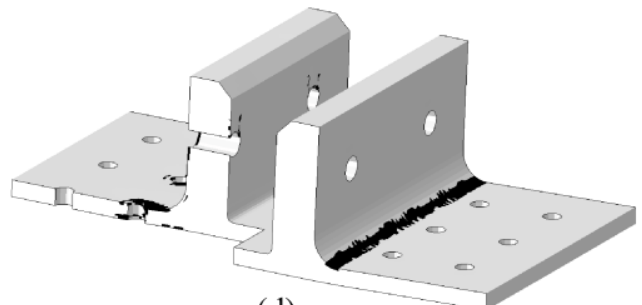

(d)

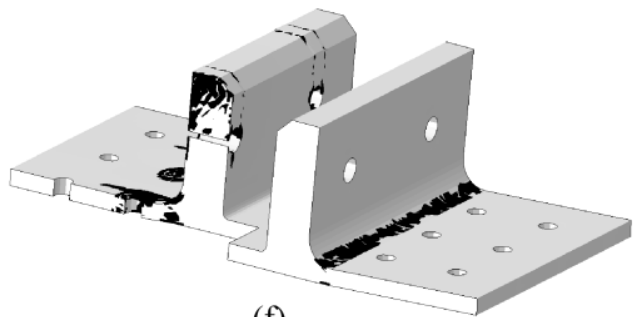

(f)

Figure 9. Typical damage evolution patterns of composite $\pi$ joint

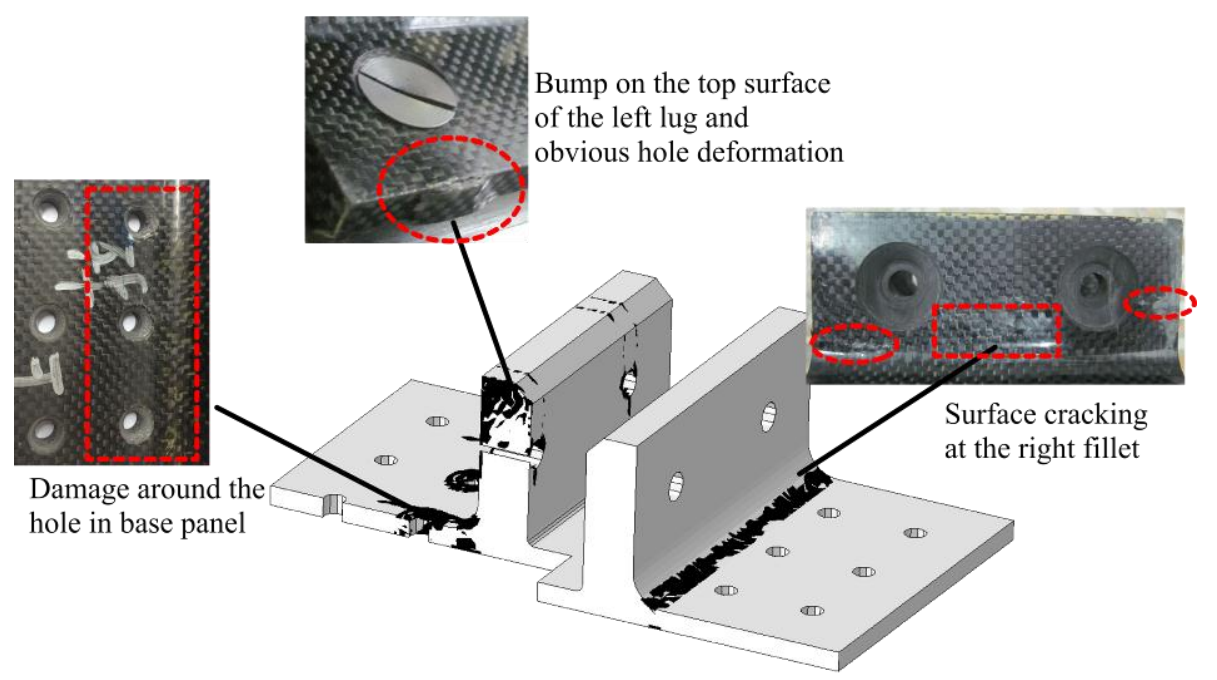

Figure 10. Experimental and predicted failure patterns of composite $\pi$ joint 
Table 1 Composite material properties

\begin{tabular}{ccc}
\hline Material & $\begin{array}{c}\text { T700 carbon/epoxy } \\
\text { composites }\end{array}$ & $\begin{array}{c}\text { G0814 carbon/epoxy } \\
\text { composite plain clothes }\end{array}$ \\
\hline Longitudinal elastic modulus, $E_{11}(\mathrm{GPa})$ & 120 & 58 \\
Transverse elastic modulus, $E_{22}(\mathrm{GPa})$ & 8.0 & 58 \\
Through-thickness elastic modulus, $E_{33}(\mathrm{GPa})$ & 8.0 & 8.0 \\
Poisson's ratio, $v_{12}, v_{13}$ & 0.33 & 0.30 \\
Poisson's ratio, $v_{23}$ & 0.48 & 0.41 \\
In-plane shear modulus, $G_{12}(\mathrm{GPa})$ & 4.0 & 4.5 \\
out-plane shear modulus, $G_{13}(\mathrm{GPa})$ & 4.0 & 4.5 \\
out-plane shear modulus, $G_{23}(\mathrm{GPa})$ & 2.7 & 2.8 \\
Longitudinal tensile strength, $X_{\mathrm{T}}(\mathrm{MPa})$ & 2000 & 500 \\
Longitudinal compressive strength, $X_{\mathrm{C}}(\mathrm{MPa})$ & 1180 & 450 \\
Transverse tensile strength, $Y_{\mathrm{T}}(\mathrm{MPa})$ & 38 & 500 \\
Transverse compressive strength, $Y_{\mathrm{C}}(\mathrm{MPa})$ & 180 & 450 \\
Through-thickness tensile strength, $Z_{\mathrm{T}}(\mathrm{MPa})$ & 38 & 38 \\
Through-thickness compressive strength, $Z_{\mathrm{C}}(\mathrm{MPa})$ & 180 & 60 \\
In-plane shear strength, $S_{12}(\mathrm{MPa})$ & 80 & 30 \\
out-plane shear strength, $S_{13}(\mathrm{MPa})$ & 80 & 80 \\
out-plane shear strength, $S_{23}(\mathrm{MPa})$ & & 50 \\
\hline
\end{tabular}


Table 2 Material degradation model

\begin{tabular}{|c|c|c|c|}
\hline \multirow{2}{*}{\multicolumn{2}{|c|}{ Failure mode }} & \multicolumn{2}{|c|}{ Material degradation model } \\
\hline & & $\begin{array}{l}\text { T700 carbon/epoxy } \\
\text { composites }\end{array}$ & $\begin{array}{c}\text { G0814 carbon/epoxy composite } \\
\text { plain clothes }\end{array}$ \\
\hline $\begin{array}{l}\text { Fiber tension } \\
\left(\sigma_{11}>0\right)\end{array}$ & & $E_{11}^{d}=0.016 E_{11}$ & $E_{11}^{d}=0.1 E_{11} \quad G_{12}^{d}=0.1 G_{12} \quad G_{13}^{d}=0.1 G_{13}$ \\
\hline $\begin{array}{l}\text { Fiber compression } \\
\left(\sigma_{11}<0\right)\end{array}$ & & $E_{11}^{d}=0.041 E_{11}$ & $E_{11}^{d}=0.2 E_{11} \quad G_{12}^{d}=0.2 G_{12} \quad G_{13}^{d}=0.2 G_{13}$ \\
\hline $\begin{array}{l}\text { Matrix tension } \\
\left(\sigma_{22}>0\right)\end{array}$ & & $E_{22}^{d}=G_{12}^{d}=G_{23}^{d}=0$ & $E_{22}^{d}=0.1 E_{22} \quad G_{12}^{d}=0.1 G_{12} \quad G_{23}^{d}=0.1 G_{23}$ \\
\hline $\begin{array}{l}\text { Matrix compression } \\
\left(\sigma_{22}<0\right)\end{array}$ & $\begin{array}{l}\sigma_{33}>0 \text { or } \sigma_{11}>0 \\
\sigma_{33}<0 \text { and } \sigma_{11}<0\end{array}$ & $\begin{array}{c}E_{22}^{d}=E_{22} \quad G_{12}^{d}=0 \quad G_{23}^{d}=0 \\
E_{22}^{d}=G_{12}^{d}=G_{23}^{d}=0\end{array}$ & $E_{22}^{d}=0.2 E_{22} \quad G_{12}^{d}=0.2 G_{12} \quad G_{23}^{d}=0.2 G_{23}$ \\
\hline $\begin{array}{l}\text { Fiber-matrix shear-out } \\
\left(\sigma_{11}<0\right)\end{array}$ & & 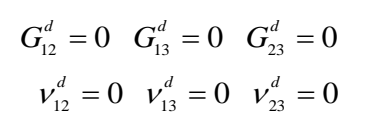 & - \\
\hline $\begin{array}{l}\text { Delamination in tension } \\
\left(\sigma_{33}>0\right)\end{array}$ & & $E_{33}^{d}=G_{23}^{d}=G_{13}^{d}=0$ & $E_{33}^{d}=0.1 E_{33} \quad G_{13}^{d}=0.1 G_{13} \quad G_{23}^{d}=0.1 G_{23}$ \\
\hline $\begin{array}{l}\text { Delamination in } \\
\text { compression } \\
\left(\sigma_{33}<0\right)\end{array}$ & $\begin{array}{l}\sigma_{22}>0 \text { or } \sigma_{11}>0 \\
\sigma_{22}<0 \text { and } \sigma_{11}<0\end{array}$ & $\begin{array}{c}E_{33}^{d}=E_{33} \quad G_{23}^{d}=0 \quad G_{13}^{d}=0 \\
E_{33}^{d}=G_{23}^{d}=G_{13}^{d}=0\end{array}$ & $E_{33}^{d}=0.2 E_{33} \quad G_{13}^{d}=0.2 G_{13} \quad G_{23}^{d}=0.2 G_{23}$ \\
\hline
\end{tabular}




\section{Graphical abstract}

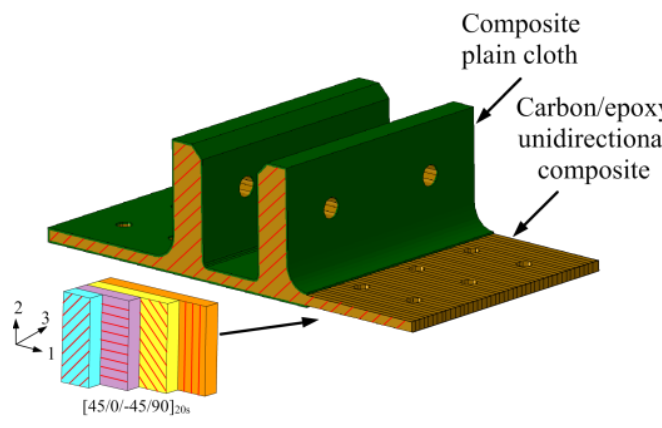

(a) Novel design configuation

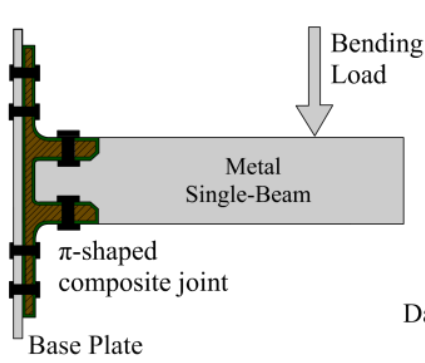

(b) Scheme view of the structure under static bending load

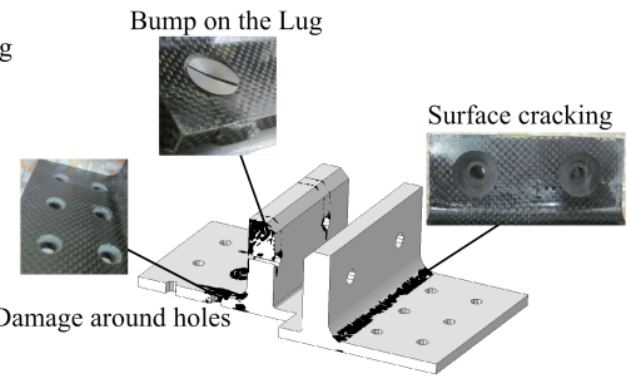

(c) Comparison of experimental and predicted final failure pattern 